\title{
Inhibition of ASC enhances the protective role of salvianolic acid $A$ in traumatic brain injury via inhibition of inflammation and recovery of mitochondrial function
}

\author{
Jing Wang ${ }^{1^{*}}$, Chao Xu ${ }^{2^{\star}}$, Kunhu Zhang ${ }^{3^{*}}$, Jianjun Shi ${ }^{1}$, Zhenyang Liu ${ }^{1}$, Xinxing Wang ${ }^{1}$, Min Guo ${ }^{1}$, Jiannan Lv $^{4}$, Xinmin Ding ${ }^{1}$ \\ ${ }^{1}$ Department of Neurosurgery, Shanxi Bethune Hospital, Shanxi Academy of Medical Science, The Third Affiliated Hospital of Shanxi \\ Medical University, Taiyuan, China, ${ }^{2}$ Department of Neurosurgery, Shanxi Corps Hospital of PAP, Taiyuan, China, ${ }^{3}$ Department of \\ Neurosurgery, Baoji Hitech People’s Hospital, Baoji, China, ${ }^{4}$ Ultrasonic Department, Characteristic Medical Centre of PAP, Tianjin, \\ China \\ *Jing Wang, Chao Xu and Kunhu Zhang contributed equally in this work.
}

\begin{abstract}
More than 50 million people are affected by traumatic brain injury (TBI) each year around the world, and nearly half of the population worldwide will have one or more TBI(s) in their lifetime. And in 2017, more than 1.39 billion people in China suffered from TBI, representing nearly $18 \%$ of the world population; these were mainly caused by road traffic incidents. Salvianolic acid $A$ is a compound obtained from Salvia miltiorrhiza Bunge, which is one of the active components of many traditional Chinese medicines for the treatment of cardiovascular and cerebrovascular disease, with the effect of inhibition of inflammatory response. ASC is a critical factor in the activation of inflammation response process via promoting the maturation of caspase-1, and activation of NLPR3 under bacterial infection promotes the necrosis of cells in an ASC-dependent manner. However, few studies focus on the effect of ASC in a TBI model. In this study, we found that inhibition of ASC reduced the expression of inflammatory cytokines, and the concentration of calcium and ROS, while it increased the expression of mitochondrial function-related proteins. We further noticed that these effects were regulated by DLK2/MLK3/JNK signalling pathway and might contribute to the treatment of TBI.
\end{abstract}

Key words: ASC, salvianolic acid A, traumatic brain injury, inflammation, mitochondria, signalling pathway.

\section{Introduction}

Traumatic brain injury (TBI) is a kind of injury caused by physical force that causes the brain to move within the skull [33]. TBI is characterised by an alteration of brain function or change in pathology [6]. The changes of brain function are related to the severity of the type of injury [37]. According to data from the World Health
Organization (WHO), TBI will be the leading cause of brain injuries by 2020. TBI might be caused by accident, violence, blunt trauma, or other factors [38], and it remains the leading cause of morbidity and mortality in the population under the age of 45 years [47]. The incidence of TBI has increased from 235 to 326 per 100,000 population per year in Europe [15], and from 
1.5 to 2 million people dead due to TBI in India each year [11]. Inflammation was also seen in other diseases caused by damage to the central nervous system (CNS), such as spinal cord injury (SCI) and peripheral nerve injury. Although the activation of inflammation response is critical for the clearance of injured cells and tissues, excessive inflammation activation after these damages can lead to secondary damage. The activation of inflammation after $\mathrm{SCl}$ and peripheral nerve injury is mainly characterised by activation of microglia, production of cytokines, and infiltration of macrophages and neutrophils. Salvianolic acid A is extracted from a traditional Chinese medicine named Salvia miltiorrhiza, and presents a variety of pharmacological functions including anti-inflammation, anti-oxidant, and anti-platelet [56]. Apoptosis-associated speck-like protein containing a caspase-recruiting domain (ASC) was first identified in 1999 as a 22-kDa protein that regulates the cellular aggregation during the apoptosis process [25]. Recently a study found that ASC could interact with Bax, a pro-apoptosis molecule, and further induce the apoptosis through the mitochondrial pathway [50]. It was also shown that Bax binds with the PYD domain of ASC and translocates Bax into mitochondria with the carrier of ASC. Further studies showed that ASC induces Bax-dependent apoptosis via activation of caspase-8. The researchers found that ASC binds with caspase-8 via NOD-like receptor NLRC4 $[12,26]$. However, the effect of ASC combined with salvianolic acid $A$ in the protection of neuronal cells after $\mathrm{TBI}$ was not fully understood. And in this experiment we established the ASC inhibition and overexpression model in cells and mice, and further established the TBI model in cells and mice. We found that inflammation response was increased and mitochondrial function was decreased after TBI with the increasing concentration of calcium and ROS, and inhibition of ASC 1 would inhibit these processes. And these effects are regulated by DLK2/MLK3/JNK signalling pathway, and they might contribute to the therapy of TBI.

\section{Material and methods}

Salvianolic acid A (SML0045) was purchased from Sigma. High glucose DMEM (10569010), Lipofectamine 3000 Transfection Reagent (1L3000150), fetal bovine serum (FBS) (10099), G418 (10131027), and puromycin (A1113803) were purchased from Thermo Fisher. Total RNA Extraction kit (R1200), MTT reagent (M8180), and TaqMan One Step RT-qPCR Kit
(T2210) were purchased from Solarbio. Quick Ligase (M2200S), HindIII (R3104S), and EcoRI (R3101S) were purchased from NEB. Esp3I (ER0452) was purchased from Thermo. Anti-Anti-NMNAT1 (ab45652, 30), PINK1 (ab23707, 66), MAVS (ab189303, 57), $\mathrm{N}$-methyl-D-aspartate receptor (NMDAR) (ab134308, 105), CaMKI (ab68234, 41), TRAF6 (ab227560, 58), p-JNK (ab239886, 48), JNK (ab208035, 48), DLK2 (ab171037, 45), p-MKK4 (ab52958, 44), MKK4 (ab33912, 44), MLK3 (ab51068, 93), Hippocalcin (ab24560, 23), SCG10 (ab115513, 21), and ASC (ab155970) antibodies were purchased from Abcam. NAD/NADH Assay (ab65348), Calcium Assay Kit (ab102505), and Complex I Rodent Profiling ELISA Kit (ab136809) were obtained from Abcam. ROS detection kits (E004-1-1) were purchased from Nanjing Jiancheng Bioengineering Institute. Annexin V-FITC/PI kit (CA1020) was purchased from Solarbio.

\section{Construction of vector}

The full-length cDNA of ASC was synthesised with the following primers: Forward: 5'-GCCTGCACTTTATAGACCAGC-3', Reverse: 5'-GCTTCCGCATCTTGCTTGG-3'. Then the PCR product of ASC was integrated into a pcDNA3.1 vector with enzymes of HindIII and EcoRI. Then cells were transfected with pcDNA3.1-ASC overexpression vector using Lipofectamine 3000 reagent according to the protocol for $48 \mathrm{~h}$, and in order to screen stable expressed cells they were cultured in $1000 \mu \mathrm{g} / \mathrm{ml}$ G418 medium. The knockdown vector of ASC was obtained as described in a previous study [42]. BsmBI was first used to digest the CRIS$P R$ vector, and annealed oligos was produced by the following primer: Forward: 5'-CACCGAAAGTAGACCGGAATCCTTG-3', Reverse: 5'-AACCAAGGATTCCGGTCTACTTTC-5'. Then annealed oligos and the CRISPR vector was ligated using Quick Ligase, according to the manufacture's protocol, to obtain ASC knockdown vector, and $2 \mu \mathrm{g} / \mathrm{ml}$ puromycin was used to screen the stable ASC knockdown cells. The adenoviruses vector was constructed according to a previous study [2]. After that, the vector was transfected to construct recombinant adenoviruses in HEK293T cells and injected into mice through the tail vein.

\section{Cell culture and grouping}

HEK293T cells (CRL-11268) and Rat hippocampus cell line H19-7 cells (CRL-2526) were obtained from ATCC and maintained under a $34^{\circ}$ humid atmosphere 
in high glucose DMEM medium supplied with $10 \%$ FBS. Then, cells were divided into 4 groups: a blank group (NC), a salvianolic acid A group (ST), a salvianolic acid A combined with ASC overexpression group (SO), and a salvianolic acid A combined with ASC knockdown group (SK). In the salvianolic acid A treatment group, cells were treated with $25 \mu \mathrm{M}$ salvianolic acid $\mathrm{A}$ for $24 \mathrm{~h}$ before performing the following experiment, and traumatic brain injury models in H19-7 cells were established as in a previous study [23]. Briefly, cells were seeded into a 6-well plate and then scratched using a sterile plastic needle after being cultured for $24 \mathrm{~h}$. Cells without treatment were used as a control.

\section{Ethical statement}

Animal studies in this experiment were performed according to the principles of the Declaration of Helsinki and the National Institutes of Health Guide for the Care and Use of Animals. Animal experiments were performed in Shanxi Dayi Hospital and under the guide of Health Animal Care and Use Committee of Shanxi Dayi hospital.

\section{Mice treatment and grouping}

Ten male C57/BL mice weight $22.5 \pm 3.2 \mathrm{~g}$ were purchased from the Laboratory Animal Centre of Southern Medical University. Five ASC knockout and 5 ASC overexpression mice with C57/BL background (20.2 $\pm 1.6 \mathrm{~g}, 10.8$ weeks old) were purchased from Cyagen (Suzhou, China). The mice were housed at $24^{\circ} \mathrm{C}$ in a humified atmosphere with a half-light/ half-dark cycle. The mice were divided into 4 groups: a controlled cortical impact (CCl) group (CG), a CCl combined with salvianolic acid $A$ treatment group (CA), a CCl combined with salvianolic acid A and ASC overexpression treatment group (CO), and a CCI combined with salvianolic acid A and ASC inhibition treatment group (Cl) [36]. In the salvianolic acid A group, the mice were first treated salvianolic acid $A$ at $20 \mathrm{mg} / \mathrm{kg}$ for 3 days through the tail vein.

\section{Construction of controlled cortical impact model}

The model of controlled cortical impact was performed as described in previous study [51]. Briefly, ketamine $(100 \mathrm{mg} / \mathrm{kg}) /$ Xylazine $(10 \mathrm{mg} / \mathrm{kg})$ was used to anaesthetise the mice via intra-peritoneal injection. Then a craniotomy was performed using a hand-held electrical drill (Dremel $10.8 \mathrm{~V}$ ), and the bone flap was removed. Then, a stereotaxic device was used to restrain the mice, which were then subjected to a $1.5-\mathrm{mm}$ deep impact (velocity of $5 \mathrm{~m} / \mathrm{s}$ ) through a computer-controlled impactor device (LinMot-Talk 1100) (impactor diameter of $2 \mathrm{~mm}$ ). Serum and brain samples of mice were stored at $-80^{\circ} \mathrm{C}$ until the following experiments were performed.

\section{Morris water maze test}

To evaluate the effect of salvianolic acid $A$ on the ameliorate brain function of mice, the Morris water maze (MWM) test was performed. Mice were kept in a circular tank of $122 \mathrm{~cm}$ diameter, which was divided into 4 quadrants. The temperature of water was kept at around $20^{\circ} \mathrm{C}$. A $10 \mathrm{~cm}^{2}$ circular platform was placed in the NE direction, and the trials were performed for 5 days, with 4 trials on each day, starting in the SE, S, NW, and W direction. The time spent on reaching the escape platform was set as the escape latency, and calculated on the $6^{\text {th }}$ day. Distance traveled in same time was calculated as the distance mice traqvelled in each quadrant when they swam for $60 \mathrm{~s}$ after the removal of the escape platform, and the number of crossed zones was counted. The results were analysed with ANY-maze software (ANY-maze).

\section{TTC staining}

Brain tissues of mice model were firstly collected and stored for $30 \mathrm{~min}$ at $-20^{\circ} \mathrm{C}$ and then cut into $2-\mathrm{mm}$ slices, followed by incubation with $2 \%$ TTC staining buffer away from light for $30 \mathrm{~min}$. The images of samples were acquired after washing with PBS buffer.

\section{Flow cytometry}

A 6-well plate was used to culture cells, and cells were treated and grouped as described previously. Trypsin was used to digest cells, and then cells were incubated in binding buffer, followed by staining with FITC at room temperature for $10 \mathrm{~min}$ and PI at room temperature for 5 min. Cells with apoptosis characteristics were screened by flow cytometry (FACSCalibur).

\section{MTT assay}

A 96-well plate was used to culture cells until the confluence reached $70-80 \%$, and cells were 
treated and grouped as previously described. After treatment, cells were then cultured with MTT buffer $(5 \mathrm{mg} / \mathrm{ml})$ at $37^{\circ} \mathrm{C}$ for $4 \mathrm{~h}$. The OD value was detected at $490 \mathrm{~nm}$ using a GENESYS $10 \mathrm{~S}$ spectrophotometer (Thermo).

\section{Extraction of cellular RNA}

Cells were first cultured in a $100-\mathrm{mm}$ plate until the confluence reached $70-80 \%$, and then cells were grouped as previously described. Then, lysis buffer was used to lyse cells and brain tissues, which were incubated at room temperature for $5 \mathrm{~min}$, followed by incubation in chloroform at room temperature for $5 \mathrm{~min}$. The water phase was removed into an adsorption column, and RNA samples were eluted with elution buffer after washing with buffer. A NanoDrop 3300 (Thermo) was used to detect the concentration of RNA samples.

\section{Quantitative polymerase chain reaction (qPCR)}

Quantitative polymerase chain reaction was performed following the instruction of manufacture's protocol of TaqMan One Step RT-qPCR Kit. The reaction was carried out with these steps: $50^{\circ} \mathrm{C}$ for $20 \mathrm{~min}$ for reverse transcription, $95^{\circ} \mathrm{C}$ for $3 \mathrm{~min}$ for degeneration; then these steps were repeated for 45 cycles: $95^{\circ} \mathrm{C}$ for $15 \mathrm{~s}$ for degeneration, $58^{\circ} \mathrm{C}$ for $20 \mathrm{~s}$ for annealing, and $72^{\circ} \mathrm{C}$ for $40 \mathrm{~s}$ for extension. The primers were as follows:

TNF- $\alpha$ (tumour necrosis factor $\alpha$ ):

5'-CGGGACGTGGAGCTGGCCGAGGAG-3'(Forward), 5'-CACCAGCTGGTTATCTCTCAGCTC-3' (Reverse); IL-6 (interleukin 6):

5'-TTCCAATGCTCTCCTAACAG-3'(Forward),

5'-CTAGGTTTGCCGAGTAGATC-3' (Reverse); IFN- $\beta$ (interferon $\beta$ ):

5'-CCACTGGCAGAAGGAACATCTGGA-3'(Forward),

5'-CTGCTTGGACTATTGTCCAGGCAC-3' (Reverse);

IL-1 $\beta$ (interleukin $1 \beta$ ):

5'-ACCTGTGTCTTTCCCGTGG-3'(Forward),

5'-TCATCTCGGAGCCTGTAGTG-3' (Reverse);

TLR2 (Toll-like receptor 2):

5'-CTGAGAATGATGTGGGCGT-3'(Forward),

5'-CTTGGTGTTCATTATCTTGCG-3' (Reverse);

TLR4 (Toll-like receptor 2):

5'-TCACCTGATACTTATTGCTGG-3'(Forward),

5'-AGTTGCCGTTTCTTGTTCT-3' (Reverse).
The $2-\Delta \Delta \mathrm{Cq}$ method was used to calculate the expression of each target gene [21]. An internal control was measured by GAPDH.

\section{Detection of each target protein using western blotting analysis}

Brain tissues and cells were lysed using RIPA lysis buffer (R0010, Solarbio), and supernatant was collected after being centrifuged for $10 \mathrm{~min}\left(4^{\circ} \mathrm{C}\right)$ at 12,000 rpm. The concentration of proteins in each group was calculated by BCA assay. Then, protein samples were separated by $10 \%$ SDS-PAGE and then transferred onto PVDF membranes. Membranes were blocked with 5\% skimmed-milk for $1 \mathrm{~h}$ at room temperature, followed by incubation with primary antibodies (1 : 1000) and secondary antibody (1: 5000). The expression of proteins was detected using chemiluminescent immunoassay. Each target protein was normalised with GAPDH.

\section{Enzyme-linked immunosorbent assay (ELISA)}

$100-\mu l$ serum samples and standard liquid were added into a 96-well plate and incubated for $4 \mathrm{~h}$ at $37^{\circ} \mathrm{C}$. Samples were reacted with streptavidin-HRP solution for $30 \mathrm{~min}$ at room temperature. After incubation with TMB solution and stop buffer, the OD value at $450 \mathrm{~nm}$ was detected using a GENESYS $10 \mathrm{~S}$ spectrophotometer (Thermo).

\section{Detection of NAD/NADH, ROS/RNS, calcium concentration}

Cells and tissue samples were prepared according to the protocol. The extracted samples were incubated at $60^{\circ} \mathrm{C}$ for $30 \mathrm{~min}$ and then cooled on ice. Standard concentration samples supplied in the kits and samples were prepared as recommended, and 100- $\mu \mathrm{l}$ samples were added into a 96-well plate and incubated for 5 min. Then NADH Developer was added and incubated for $4 \mathrm{~h}$, and after incubation with stop buffer, the OD value was detected using a GENESYS $10 \mathrm{~S}$ spectrophotometer $(450 \mathrm{~nm})$.

\section{Statistical analysis}

The present data were presented as mean \pm SD, and the experiment was independently repeated 3 times. Differences between groups were detected 
using one-way ANOVA analysis. $P<0.05$ was regarded as a significant difference.

\section{Results}

\section{Detection of proliferation ability of cells under salvianolic acid A treatment}

The proliferation rate in the NC, ST, SK, and SO groups were $83.4 \pm 6.3,99.1 \pm 8.1,125.2 \pm 10.3$, and 80.2 \pm 6.0 , respectively (Fig. $1 \mathrm{~A}$ ). The proliferation rate was significantly increased after salvianolic acid A treatment ( $p<0.05)$, and overexpression of ASC could enlarge this effect while knockdown of ASC would reduce this effect. The expression of ASC in brain tissues of mice and H19-7 cells was detected (Fig. 1B and C). Expression of ASC in the overexpression group was increased, and it was decreased in the ASC knockdown group compared with the NC group. These results indicate that the experiment models were successfully established.

\section{The effect of tanshinone IIA on the brain function of mice}

The average escape latencies of mice were as follows: $78.1 \pm 7.2,70.3 \pm 6.6,62.2 \pm 5.3,51.7 \pm 4.9$, and $46.8 \pm 4.3$ in the NC group; $72.0 \pm 6.6,65.4$ $\pm 6.1,59.3 \pm 5.7,48.4 \pm 5.3$, and $42.0 \pm 4.2$ in the ST group; $63.1 \pm 6.2,58.2 \pm 5.5,51.0 \pm 4.9,40.3 \pm 4.1$,

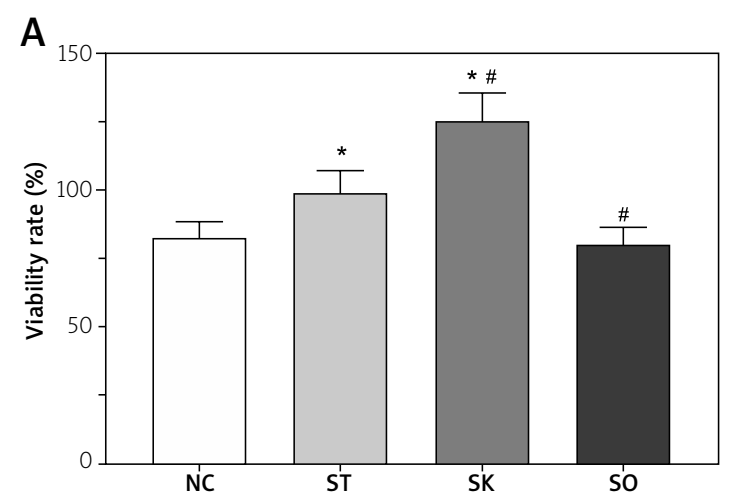

B
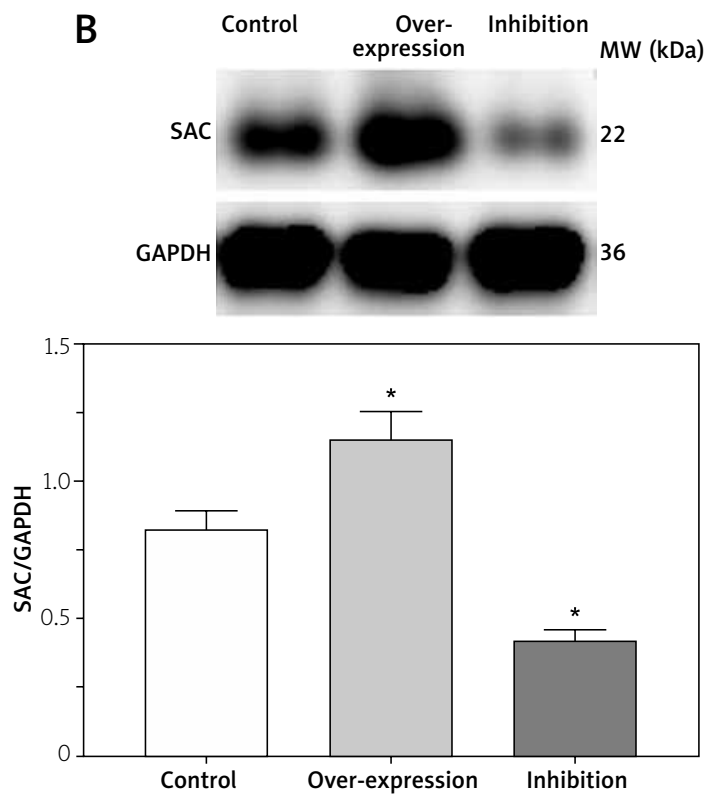

C Control $\underset{\substack{\text { Over- } \\ \text { expression }}}{\text { Inhibition }} \mathrm{MW}(\mathrm{kDa})$
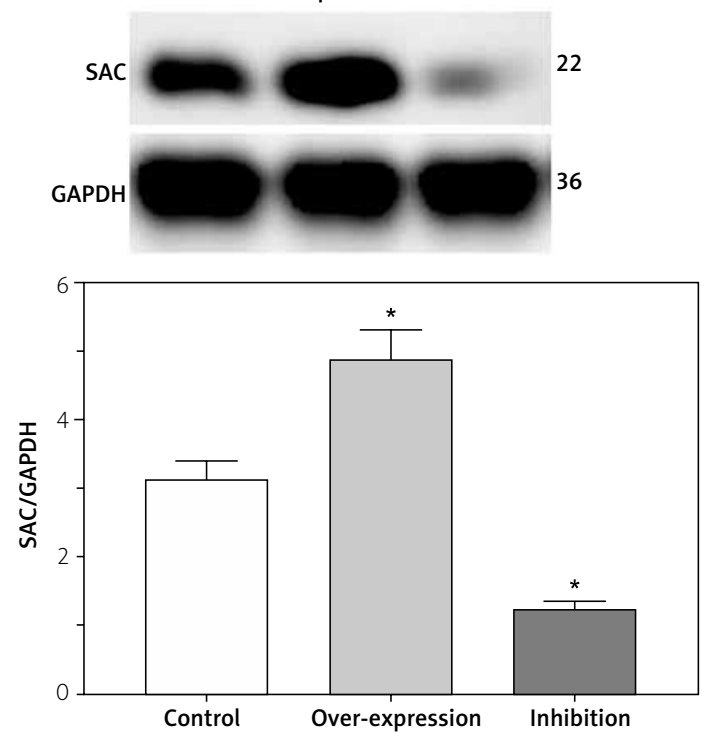

Fig. 1. Viability rate of H19-7 cells in each group and expression of ASC in H19-7 cells and brain tissues. A) Viability rate of H19-7 cells. B) Expression of ASC in H19-7 cells. C) Expression of ASC in brain tissues. Data presented as mean \pm SD. Each experiment was repeated 3 times independently. GAPDH was used as an internal control. $p<0.05$ was set as a statistical difference; ${ }^{*} p<0.05$ compared with NC or CA group; ${ }^{\#} p<0.05$ compared with ST or CG group. 

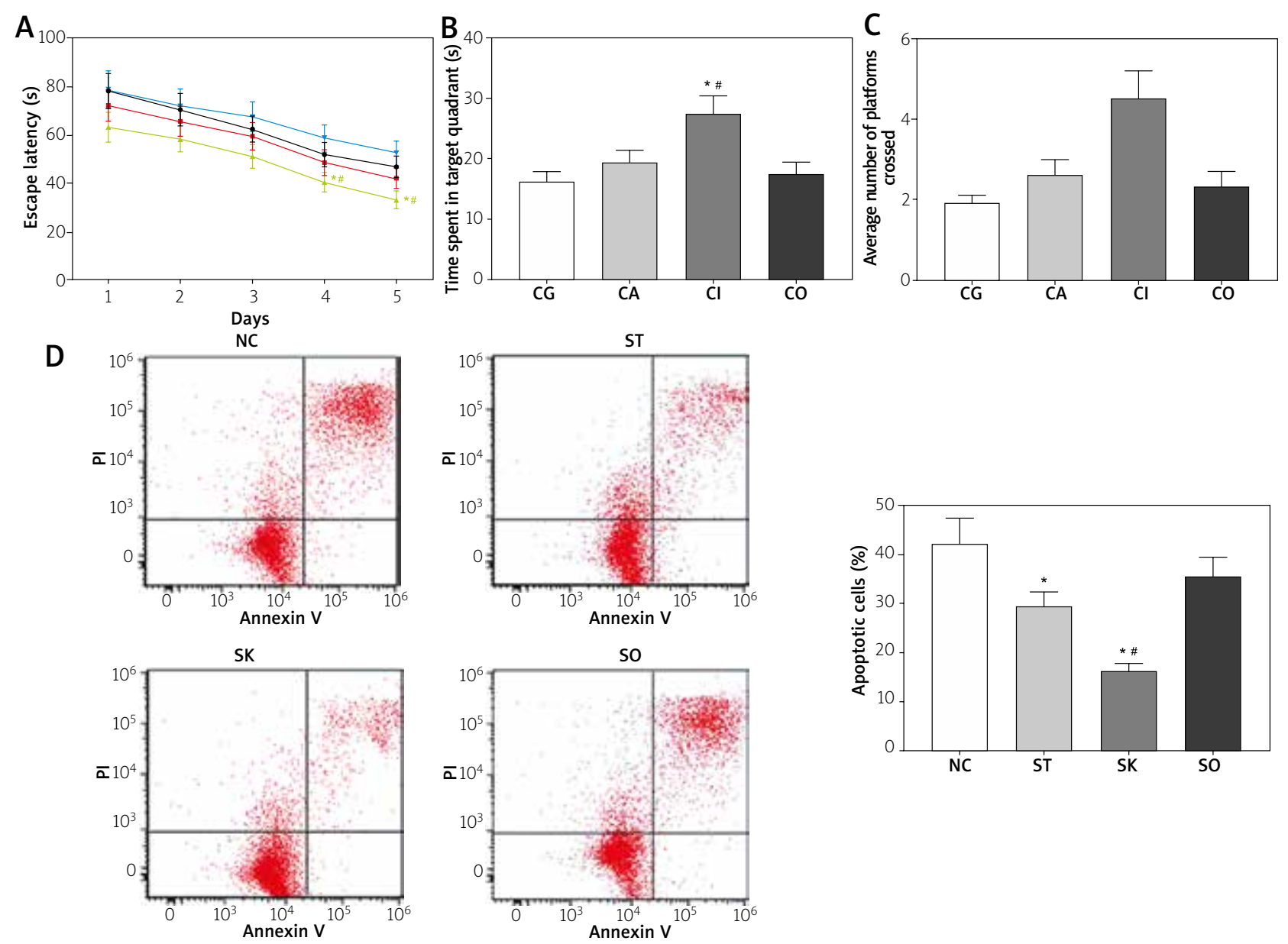

$\mathrm{E}$ CG

CA

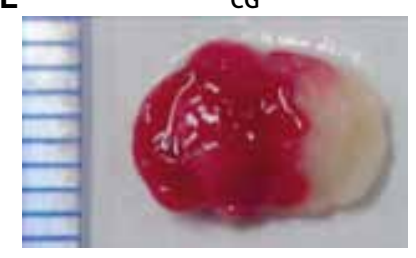

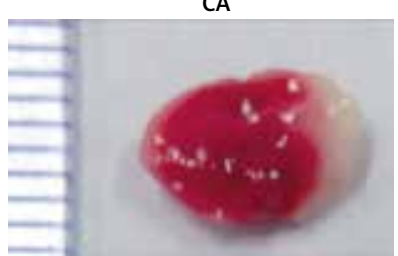
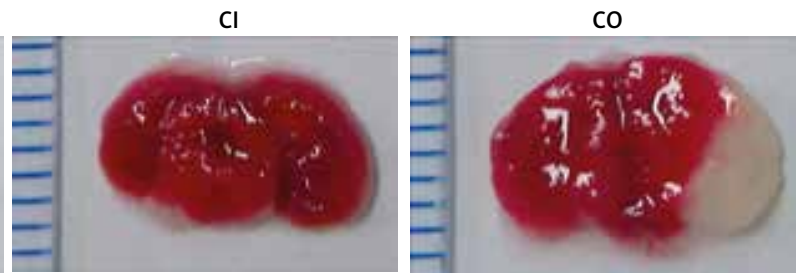

Fig. 2. Behaviour tests in mouse model and detection of apoptotic cells. A) Average escape latency of mice in each group. B) Average number of platforms crossed by mice in each group. C) Time spent in target quadrant of mice in each group. D) Detection of apoptotic cells in cell model using flow cytometry. E) TTC staining of brain tissues of mice in each group. Data presented as mean \pm SD. Each experiment was repeated 3 times independently. $p<0.05$ was set as a statistical difference; ${ }^{*} p<0.05$ compared with NC or CA group; ${ }^{\#} p<0.05$ compared with ST or CG group.

and $33.1 \pm 3.6$ in the SK group; and 78.5 $\pm 7.7,72.0$ $\pm 6.8,67.5 \pm 6.1,58.6 \pm 5.4$, and $52.3 \pm 5.1$ in the SO group in a continuous 5 -day period (Fig. 2A). The average number of platforms crossed was 1.9 $\pm 0.2,2.6 \pm 0.4,4.5 \pm 0.7$, and $2.3 \pm 0.4$ (Fig. 2B). The time spent in the target quadrant was $16.2 \pm 1.6$, $19.3 \pm 2.2,27.4 \pm 3.1$, and $17.3 \pm 2.1 \mathrm{~s}$ (Fig. 2C). These results show that brain function was significant- ly increased after treatment with salvianolic acid A combined with inhibition of SAC. The apoptotic cells in the NC, ST, SK, and SO groups were 49.2 $\pm 4.3,28.5$ $\pm 2.9,16.3 \pm 2.0$, and $40.4 \pm 3.6$, respectively (Fig. 2D). The area of infraction was detected using TCC staining (Fig. 2E). These results show that salvianolic acid A with inhibition of SAC reduced apoptosis of cells after TBI. 


\section{Expression of inflammatory-related genes in H19-7 cells and brain tissues}

The expression levels of TNF- $\alpha$ in the NC, ST, SK, and $\mathrm{SO}$ groups were $1.32 \pm 0.15,1.06 \pm 0.10,0.83 \pm 0.07$, and $1.29 \pm 0.14$, respectively. The expression levels of IL-6 were $1.22 \pm 0.08,0.94 \pm 0.07,0.70 \pm 0.05$, and 1.09 \pm 0.08 , respectively. The expression levels of IFN- $\beta$ were $1.09 \pm 0.08,0.90 \pm 0.06,0.62 \pm 0.04$ and $1.18 \pm 0.09$, respectively. The expression levels of IL-1 $\beta$ were 1.56 $\pm 0.16,1.21 \pm 0.09,0.82 \pm 0.07$, and $1.35 \pm 0.12$, respectively. The expression levels of TLR2 were $1.35 \pm 0.10$, $1.10 \pm 0.08,0.81 \pm 0.06$, and $1.30 \pm 0.09$, respectively. The expression levels of TLR4 were $1.40 \pm 0.14,1.15$ $\pm 0.10,0.81 \pm 0.07$, and $1.46 \pm 0.13$, respectively (Fig. 3). The expression levels of TNF- $\alpha$ in the CG, CA, Cl, and CO groups were $1.62 \pm 0.18,1.36 \pm 0.15,1.13 \pm 0.11$, and $1.47 \pm 0.15$, respectively. The expression levels of IL-6 were $1.52 \pm 0.16,1.24 \pm 0.14,1.02 \pm 0.09$, and 1.36 \pm 0.12 , respectively. The expression levels of IFN- $\beta$ were $1.61 \pm 0.14,1.30 \pm 0.11,1.05 \pm 0.08$, and $1.41 \pm 0.13$, respectively. The expression levels of IL-1 $\beta$ were 1.88 $\pm 0.17,1.32 \pm 0.14,1.00 \pm 0.08$, and $1.49 \pm 0.15$, respectively. The expression levels of TLR2 were $1.52 \pm 0.13$, $1.27 \pm 0.11,1.03 \pm 0.09$, and $1.42 \pm 0.12$, respectively. The expression levels of TLR4 were $1.62 \pm 0.17,1.38$ $\pm 0.14,1.07 \pm 0.09$, and $1.67 \pm 0.19$, respectively (Fig. 4). These results show that salvianolic acid $A$ decreased the expression of inflammatory-related cytokines at the transcription level, and inhibition of ASC would enlarge these effects, while overexpression of ASC might reduce the effects of salvianolic acid $A$.

\section{Expression of mitochondrial function-related proteins}

The NMNAT1 expression in the H19-7 cells of the NC, ST, SK, and SO groups were $0.27 \pm 0.02$, $0.72 \pm 0.06,1.17 \pm 0.10$, and $0.76 \pm 0.06$, respectively. NMNAT1 expression was increased in all treatment groups compared with the NC group ( $p<0.05)$, and it was increased in the SK group compared with the ST group $(p<0.05)$. NMDAR expression was $1.84 \pm 0.15$, $0.97 \pm 0.08,0.70 \pm 0.06$, and $1.10 \pm 0.09$, respectively. NMDAR expression was decreased in all treatment groups compared with the NC group ( $p<0.05)$, and it was decreased in the SK group compared with the ST group $(p<0.05)$. The PINK1 expression was 1.80 $\pm 0.15,1.45 \pm 0.12,0.96 \pm 0.08$, and $1.26 \pm 0.10$, respectively. Changes in PINK1 expression were similar to the changes in NMDAR expression. MAVS expression was $1.76 \pm 0.15,0.86 \pm 0.07,0.37 \pm 0.03$, and 0.58
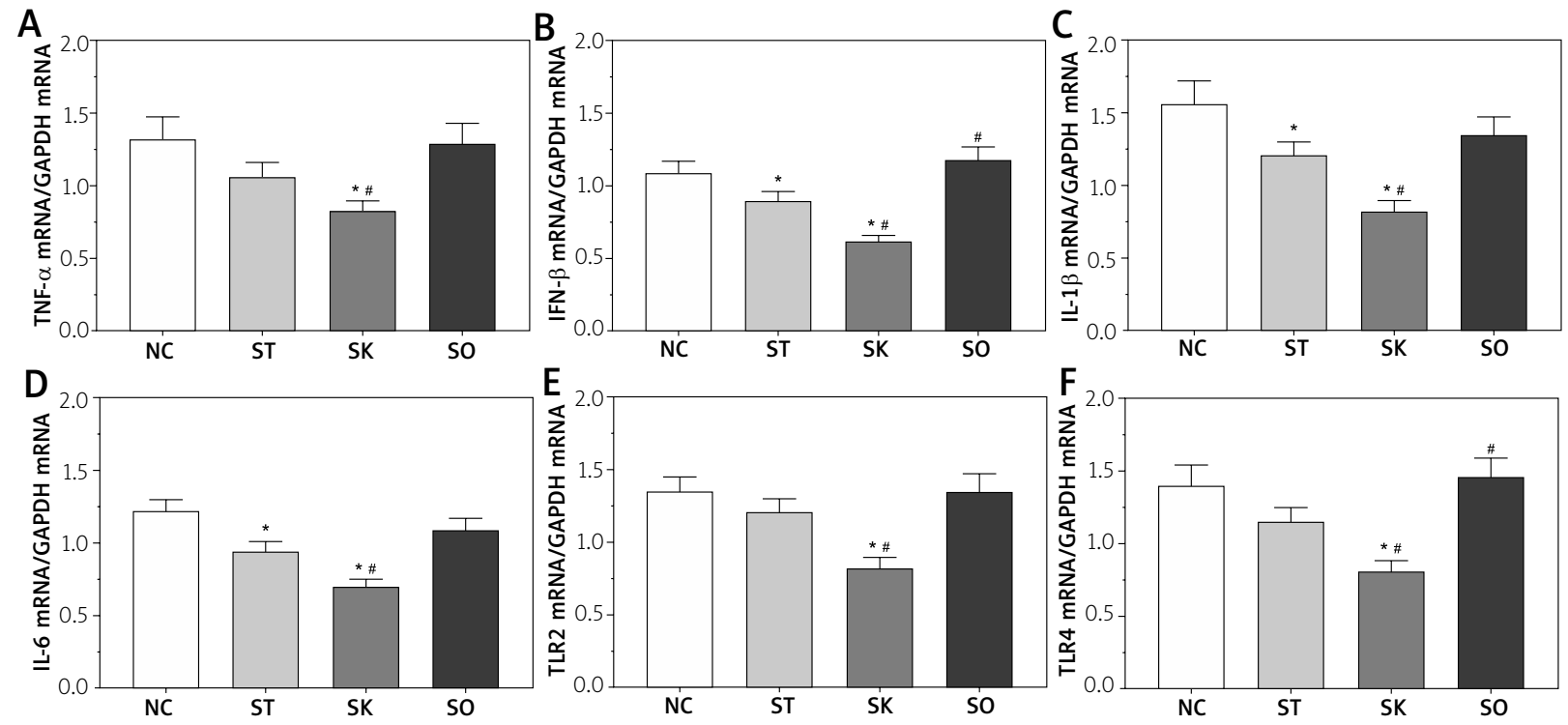

Fig. 3. Expression of inflammatory-related genes in H19-7 cells. A) Expression of TNF- $\alpha$ in each group of H19-7 cells. B) Expression of IFN- $\beta$ in each group of H19-7 cells. C) Expression of IL-1 $\beta$ in each group of H19-7 cells. D) Expression of IL-6 in each group of H19-7 cells. E) Expression of TLR2 in each group of H19-7 cells. F) Expression of TLR4 in each group of H19-7 cells. Data presented as mean \pm SD. Each experiment was repeated 3 times independently. GAPDH was used as an internal control. $p<0.05$ was set as a statistical difference; ${ }^{*} p<0.05$ compared with NC group; ${ }^{*} p<0.05$ compared with ST group. 
A
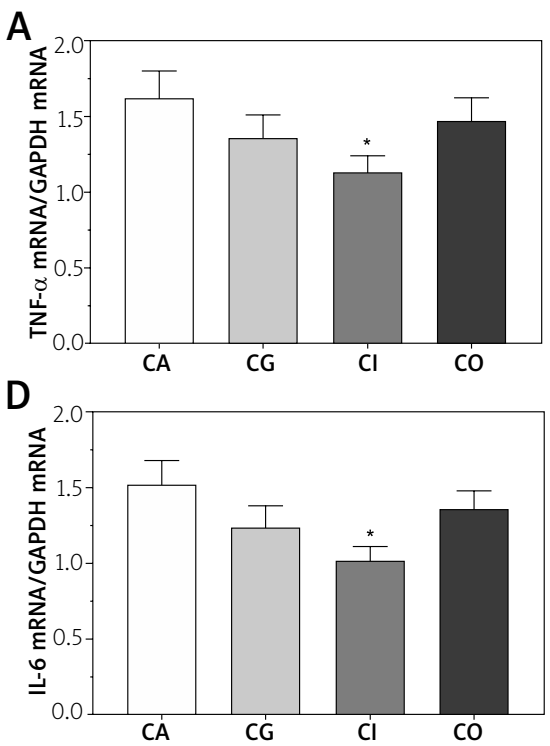
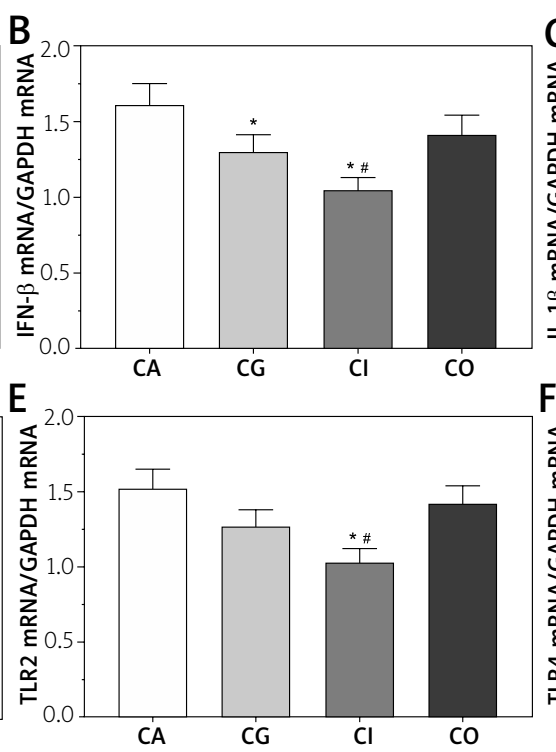
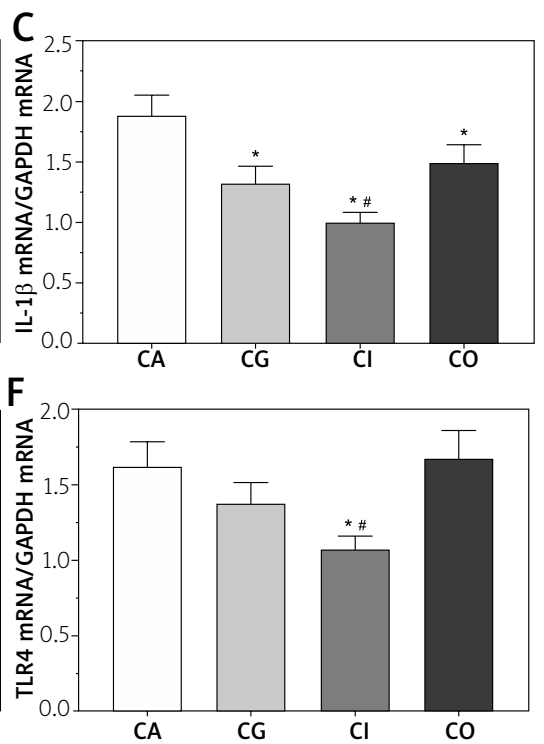

Fig. 4. Expression of inflammatory-related genes in brain tissues. A) Expression of TNF- $\alpha$ in each group of brain tissues. B) Expression of IFN- $\beta$ in each group of brain tissues. C) Expression of IL-1 $\beta$ in each group of brain tissues. D) Expression of IL-6 in each group of brain tissues. E) Expression of TLR2 in each group of brain tissues. F) Expression of TLR4 in each group of brain tissues. Data presented as mean \pm SD. Each experiment was repeated 3 times independently. GAPDH was used as an internal control. $p<0.05$ was set as a statistical difference; ${ }^{*} p<0.05$ compared with CA group; ${ }^{*} p<0.05$ compared with CG group.

\pm 0.05 , respectively. MAVS expression was decreased in all treatment groups compared with the NC group $(p<0.05)$, and it was decreased in the SK and SO groups compared with the ST group $(p<0.05)$. TRAF6 expression was $1.72 \pm 0.14,0.98 \pm 0.08,0.31 \pm 0.026$, and $1.03 \pm 0.09$, respectively. Changes in TRAF6 expression were similar to the changes in PINK1 and NMDAR. CaMKI expression was $1.62 \pm 0.14$, $1.55 \pm 0.13,1.22 \pm 0.10$, and $2.00 \pm 0.17$, respectively (Fig. 5). NMNAT1 expression in the CG, CA, Cl, and CO groups was $0.38 \pm 0.03,0.87 \pm 0.07,0.88 \pm 0.07$, and $0.65 \pm 0.05$, respectively. NMDAR expression was 0.88 $\pm 0.07,0.88 \pm 0.07,0.80 \pm 0.07$, and $1.18 \pm 0.10$, respectively. PINK1 expression was $1.16 \pm 0.10,1.31 \pm 0.11$, $0.94 \pm 0.08$, and $1.36 \pm 0.11$, respectively. MAVS expression was $0.63 \pm 0.05,0.64 \pm 0.05,0.67 \pm 0.06$, and 1.23 \pm 0.10 , respectively. TRAF6 expression was $0.69 \pm 0.06$, $0.79 \pm 0.07,0.49 \pm 0.04$, and $1.17 \pm 0.10$, respectively. CaMKI expression was $0.90 \pm 0.08,0.98 \pm 0.08,0.76$ \pm 0.06 , and $1.15 \pm 0.10$, respectively (Fig. 6).

\section{Activation of JNK/MLK3 signalling pathway}

DLK2 expression in H19-7 cells of the NC, ST, SK, and $\mathrm{SO}$ groups was $0.74 \pm 0.06,0.86 \pm 0.07,0.43 \pm 0.04$, and $0.80 \pm 0.07$, respectively. The ratio of $p-M K K 4 /$
MKK 4 was $0.37 \pm 0.03,0.81 \pm 0.07,0.85 \pm 0.07$, and 0.81 \pm 0.07 , respectively. MLK3 expression was $0.67 \pm 0.06$, $0.66 \pm 0.05,0.06 \pm 0.01$, and $0.70 \pm 0.06$, respectively. The ratio of $p-J N K / J N K$ was $2.03 \pm 0.17,1.47 \pm 0.12$, $0.60 \pm 0.05$, and $1.42 \pm 0.12$, respectively. Hippocalcin expression was $0.26 \pm 0.02,0.30 \pm 0.03,0.57 \pm 0.05$, and $0.45 \pm 0.04$, respectively. SCG10 expression was $0.40 \pm 0.03,0.77 \pm 0.06,0.83 \pm 0.07$, and $0.41 \pm 0.03$, respectively (Fig. 7). DLK2 expression in the $\mathrm{CG}, \mathrm{CA}, \mathrm{Cl}$, and $\mathrm{CO}$ groups was $0.70 \pm 0.06,0.71 \pm 0.06,0.63 \pm 0.05$, and $1.12 \pm 0.09$, respectively. The ratio of $\mathrm{p}-\mathrm{MKK} 4 /$ MKK4 was $0.44 \pm 0.04,0.63 \pm 0.05,0.71 \pm 0.06$, and 0.46 \pm 0.04 , respectively. MLK3 expression was $1.51 \pm 0.13$, $1.14 \pm 0.09,0.88 \pm 0.07$, and $1.41 \pm 0.12$, respectively. The ratio of $p-J N K / J N K$ was $1.23 \pm 0.10,1.17 \pm 0.10,0.58$ \pm 0.05 , and $1.16 \pm 0.10$, respectively. The hippocalcin expression was $0.47 \pm 0.04,0.71 \pm 0.06,0.88 \pm 0.07$, and $0.87 \pm 0.07$. SCG10 expression was $0.60 \pm 0.05,0.98$ $\pm 0.08,1.11 \pm 0.09$, and $0.73 \pm 0.06$, respectively (Fig. 8).

\section{Detection of cellular calcium concentration, complex I, cellular ROS, and the ratio of NAD/NADH in H19-7 cells and brain tissues}

The concentration of NADH in the NC, ST, SK, and SO groups of H19-7 cells was $52.3 \pm 12.2,86.1 \pm 17.1,145.5$ 

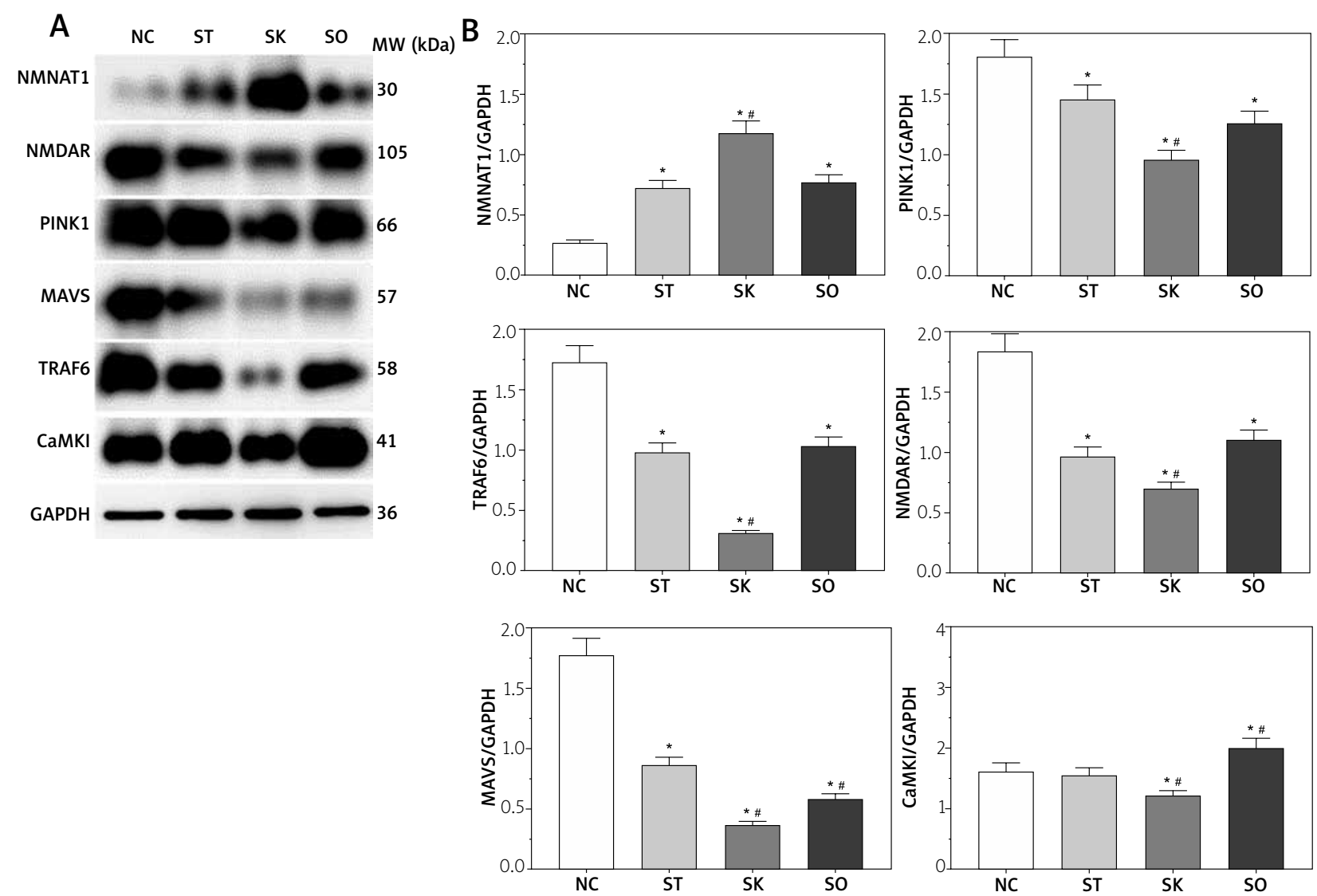

Fig. 5. Expression of mitochondrial function-related proteins in H19-7 cells. A) Expression of NMNAT1, NMDAR, PINK1, MAVS, TRAF6, and CaMKI in each group of H19-7 cells. B) Quantitative analysis of each target protein. Data presented as mean \pm SD. Each experiment was repeated 3 times independently. GAPDH was used as an internal control. $p<0.05$ was set as a statistical difference; ${ }^{*} p<0.05$ compared with NC group; ${ }^{\#} p<0.05$ compared with ST group.

\pm 20.4 , and $84.0 \pm 17.2 \mathrm{nM}$, and the concentration of NADH in the $\mathrm{CG}, \mathrm{CA}, \mathrm{Cl}$, and $\mathrm{CO}$ groups was $90.2 \pm 17.3,135.1$ $\pm 21.6,194.2 \pm 26.5$, and $120.4 \pm 18.4 \mathrm{nM}$, respectively. The concentration of NADH was increased in the ST and SK groups compared with the NC group $(p<0.05)$, and it was increased in the SK group compared with the ST group $(p<0.05)$. The concentration of calcium was 19.3 $\pm 3.1,14.2 \pm 2.2,8.1 \pm 1.1$, and $14.3 \pm 2.3 \mathrm{mM}$, respectively, and the concentration of calcium in the CG, $\mathrm{CA}, \mathrm{Cl}$, and $\mathrm{CO}$ groups was $23.2 \pm 4.6,17.6 \pm 2.2$, $11.7 \pm 1.1$, and $16.8 \pm 2.9 \mathrm{mM}$, respectively (Fig. 9). The changes in concentration of calcium in each group presented a similar trend as changes in $\mathrm{NADH}$. The concentration of complex I in each group of H19-7 cells was $294.5 \pm 27.6,260.1 \pm 23.1,196.3 \pm 17.2$, and $250.6 \pm 19.4 \mu \mathrm{g} / \mathrm{ml}$, respectively, and the concentration of complex I was significantly decreased in the SK group compared with the NC group and
ST group $(p<0.05)$. The concentration of complex I in the $\mathrm{CG}, \mathrm{CA}, \mathrm{Cl}$, and $\mathrm{CO}$ groups was $398.5 \pm 28.1,320.6$ $\pm 25.2,280.1 \pm 20.4$, and $304.7 \pm 22.9 \mu \mathrm{g} / \mathrm{ml}$, respectively, and the concentration of complex I was decreased in the SK group compared with the NC and ST group $(p<0.05)$. The relative intensity of ROS in the NC, ST, SK, and $\mathrm{SO}$ groups of $\mathrm{H} 19-7$ cells was $1.00 \pm 0.09,1.33 \pm 0.13$, $1.72 \pm 0.16$, and $1.20 \pm 0.11$, respectively, and the relative intensity of ROS in the CG, $\mathrm{CA}, \mathrm{Cl}$, and $\mathrm{CO}$ groups was 1.00 $\pm 0.09,1.32 \pm 0.14,1.75 \pm 0.17$, and $1.18 \pm 0.10$, respectively. The relative intensity of ROS was significantly increased in the ST and SK groups compared with the NC group $(p<0.05)$, and it was significantly increased in the SK group compared with the ST group $(p<0.05)$.

\section{Discussion}

Traumatic brain injury affects more than 2.8 million people every year [41]. TBI is a unique from of 

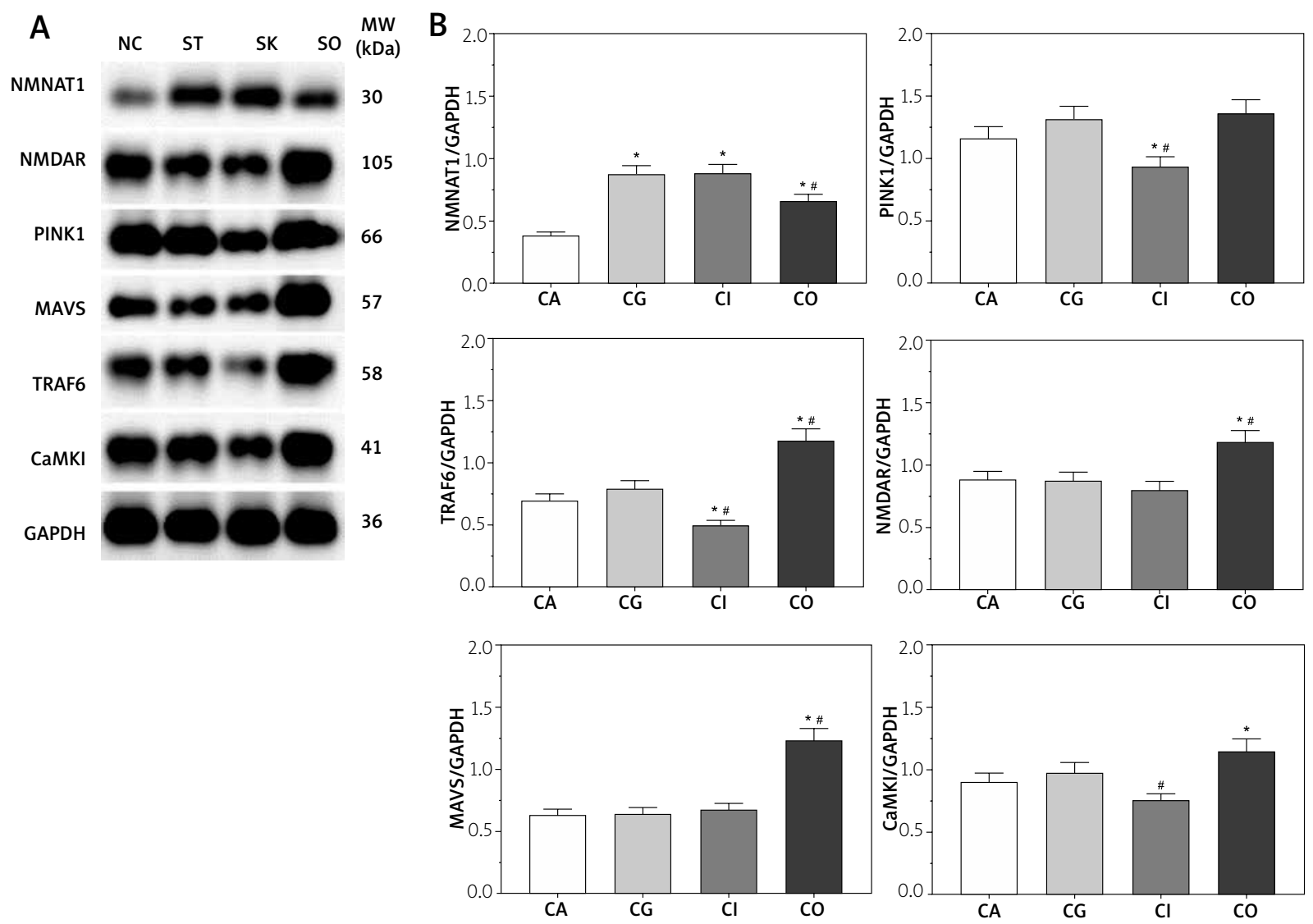

Fig. 6. Expression of mitochondrial function-related proteins in brain tissues. A) Expression of NMNAT1, NMDAR, PINK1, MAVS, TRAF6, and CaMKI in each group of brain tissues. B) Quantitative analysis of each target protein. Data presented as mean \pm SD. Each experiment was repeated 3 times independently. GAPDH was used as an internal control. $p<0.05$ was set as a statistical difference; ${ }^{*} p<0.05$ compared with CA group; ${ }^{\#} p<0.05$ compared with CG group.

neurological affliction, which is caused by a biomechanical event, followed by a secondary injury caused by diverse positive-feedback cascades including neuro-inflammation, cellular apoptosis, blood-brain barrier (BBB) disruption, and mitochondrial dysfunction, which exacerbates the dysfunction of neuron cells and loss of tissue [48]. ASC is firstly regarded as the silencing gene related to methylation in cancer cells [8]. ASC is located in the nucleus under normal conditions but translocates into cytoplasm in activation conditions [30]. ASC was regarded as an inflammasome adaptor that performed a pro-inflammation function [27]. A recent study noticed that ASC might induce inflammation and cancer invasion and metastasis [29]. Multiple pro-inflammatory cytokines exist in the CNS, and they are mainly under the regulation of IL- $1 \beta$ and TNF- $\alpha$. Briefly, TNF- $\alpha$ activates NLRP3 and further activates caspase-1, leading to the con- version of pro-IL-1 $\beta$ into IL-1 $1 \beta$, further inducing the activation of TNF- $\alpha$ [22]. A previous study also found that TNF- $\alpha$ is the central regulator of the inflammatory regulation system, and a number of biological drugs aimed at TNF- $\alpha$ and IL-1 $\beta$ could both induce the expression and secretion of IL-6 [43]. These cytokines participate in multiple important cellular activities and were secreted into circulation, and thus these cytokines were regarded as a biological marker for inflammatory reaction. Also, TNF- $\alpha$, IL-1 $1 \beta$, and IL-6 present multiple functions in the CNS; these cytokines could regulate the systemic host responses induced by inflammation caused by disease or local alterations, as well as the clinical application of IFN- $\beta$ in the reduction of clinical progression and inflammatory lesions [49]. Researchers have focused on the application and clinical efficacy of IFN- $\beta$, but the pharmacodynamic usage of IFN- $\beta$ remains poor- 

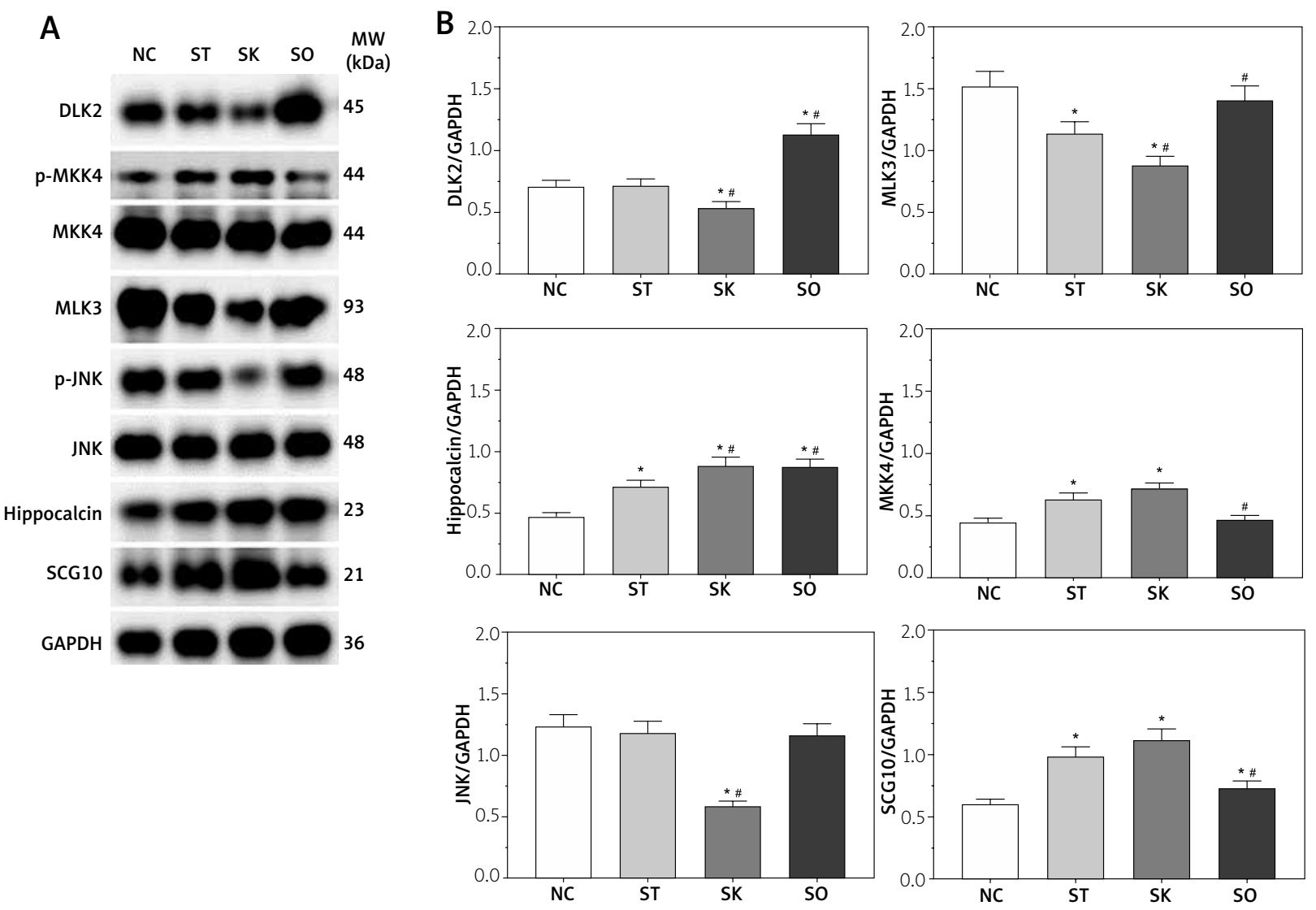

Fig. 7. Activation of DLK2/MLK3/JNK signalling pathway in H19-7 cells. A) Expression of DLK2, p-MKK4, MKK4, MLK3, p-JNK, JNK, hippocalcin, and SCG10 in each group of H19-7 cells. B) Quantitative analysis of each target protein. Data presented as mean \pm SD. Each experiment was repeated 3 times independently. GAPDH was used as an internal control. $p<0.05$ was set as a statistical difference; ${ }^{*} p<0.05$ compared with NC group, ${ }^{\#} p<0.05$ compared with ST group.

ly understood. A recent study demonstrates the anti-inflammatory effect of IFN- $\beta$ in astrocytes, so treatment of IFN- $\beta$ would result in the activation of anti-inflammatory genes at the transcriptional level; besides, IFN- $\beta$ treatment could also decrease the permeability of the BBB, and deletion of IFN- $\beta$ in astrocytes facilitates the translation of viruses into CNS [9]. Toll-like receptors could stimulate the secretion of cytokines and antiviral interferons in immune cells and endothelial cells. Previous studies using PCR arrays found that among all members of TLRs, TLR2 and TLR4 are increased in brain tissue $24 \mathrm{~h}$ after TBI, and the expressions of these genes were increased to a peak at $7 \mathrm{~d}$ and began to decline at $14 \mathrm{~d}$ [14]. TLR2 and TLR4 in the CNS were mainly secreted by macrophages/microglia. in another study, TLR4-positive cells were located at the same site as neural stem cells (NSCS), and TLR4 expression was increased, peaking 3 days after injury [54], indicating that TLR4 was associated with the process of neurogenesis. Previous studies indicated that TLR2 and TLR4 are closely related to inflammatory response in brain tissue at the injured site, and they are related to the pathological processes of secondary injury following TBI. Here, we noticed that salvianolic acid $A$ treatment decreased the expression of these cytokines at transcription levels, resulting in inhibition of inflammation response induced by TBI, further reducing the secondary injury induced by inflammation after TBI. We also noticed that reduction in ASC expression enhanced the role of salvianolic acid A throughout the treatment process of TBI.

Mitochondria are critical for maintaining the energy supply for neuronal cell survival. A previous study also found that dysfunction of mitochondria is a distinctive characteristic of TBI. Dysfunction of 

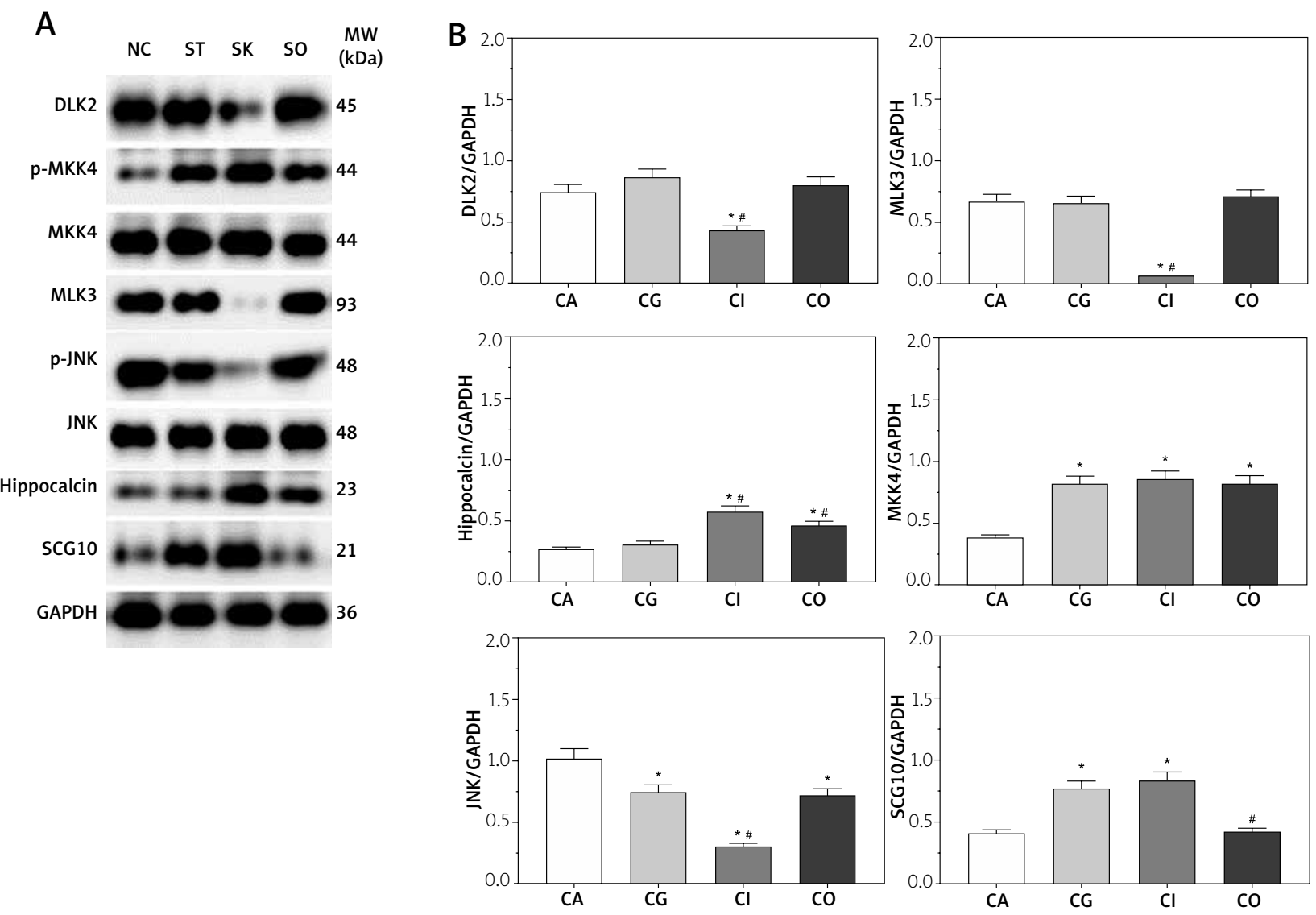

Fig. 8. Activation of DLK2/MLK3/JNK signalling pathway in brain tissues. A) Expression of DLK2, p-MKK4, MKK4, MLK3, p-JNK, JNK, hippocalcin, and SCG10 in each group of brain tissues. B) Quantitative analysis of each target protein. Data presented as mean \pm SD. Each experiment was repeated 3 times independently. GAPDH was used as an internal control. $p<0.05$ was set as a statistical difference; ${ }^{*} p<0.05$ compared with CA group; ${ }^{*} p<0.05$ compared with CG group.

mitochondria reduce the function of the respiratory chain and the reserve of energy supply, with an increase in free radical production and mitochondrial calcium accumulation [55]. Alteration of the expression of proteins related to mitochondria reflected the alteration in mitochondria function after TIBI. Using a mouse model, a recent study found that non-nuclear localised NMNAT1 reduced the number of strokes after hypoxic ischaemic insult [32]. A previous study found that overexpression of NMNAT1 in cultured dorsal root ganglia (DRG) cells could delay the degeneration of cells after axotomy [44], and this effect was also observed in cultured DRG cells after exposure to vincristine. Besides, PTEN-induced putative kinase 1 (PINK1) exists in cytosol and also targets the outer mitochondrial membrane. PINK1 is a unique molecule for maintaining mitochondria function. In normal status, PINK1 is constitutively imported through translocases of the outer (TOM) complex, via interaction with the surface receptors and combined with TOM40 [18]. A previous study found that deletion of PINK1 increased the oxidative stress level in mitochondria, and binding of PINK1 and Parkin would tag the damaged mitochondria via the ubiquitin pathway [10]. The phagocytosis process could also be impaired by depletion of PINK1, leading to enlarged lysosomal vacuoles. Spermidine could also induce the formation of mitophagosomes and decrease the aggregation of dysfunction mitochondria via the PINK1/Parkin pathway [35]. Another important protein related to mitochondrial function is MAVS. MAVS was discovered in 2005, localised on the outer membrane of mitochondria and consisting of an N-terminal CARD domain, a proline-rich region (PRR), and a C-terminal transmembrane domain (TM). Without the TM domain, MAVS would lose the 

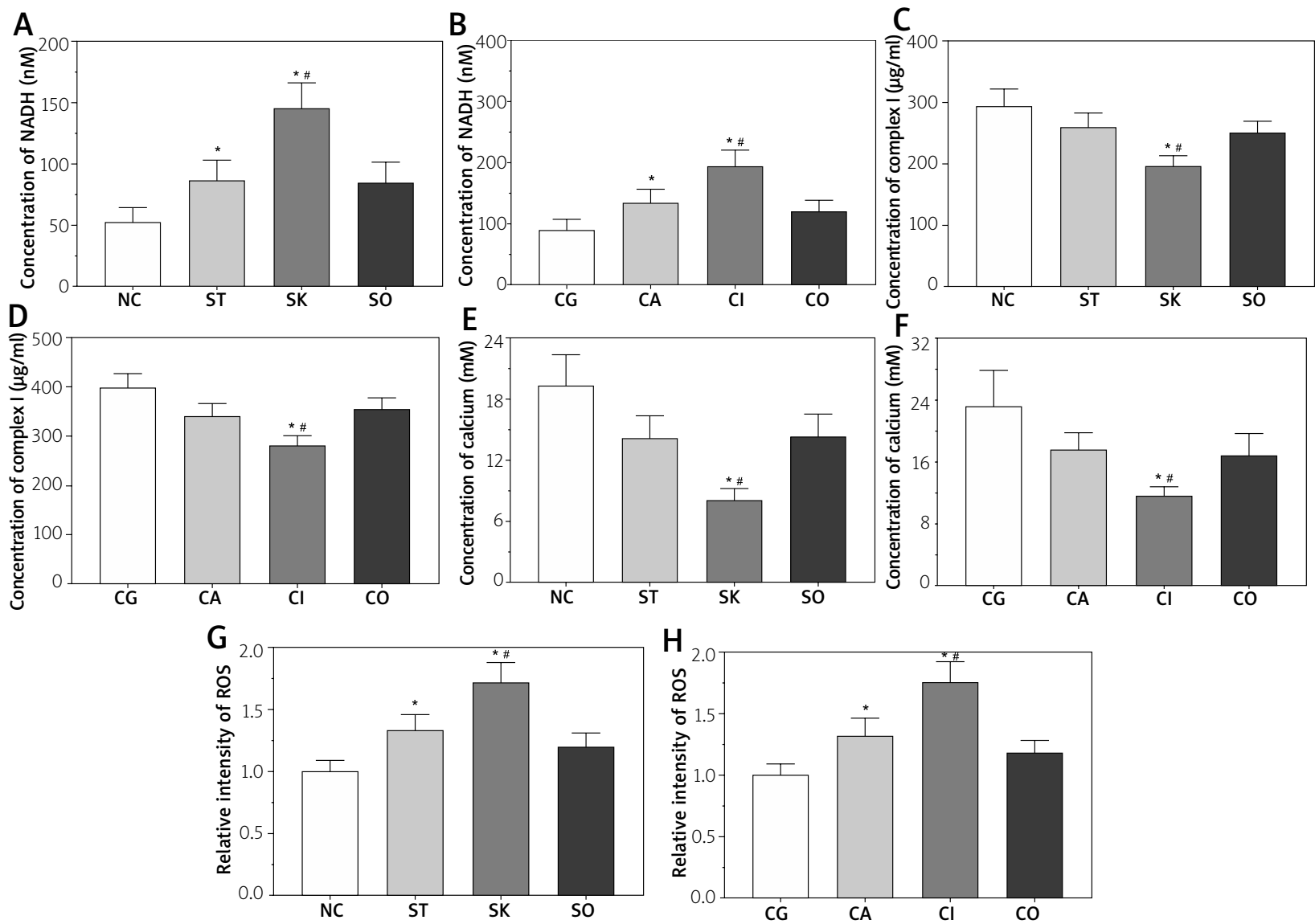

Fig. 9. Concentration of NADH, mitochondrial complex I, calcium, and ROS in H19-7 cells and brain tissues. A) Concentration of NADH in H19-7 cells. B) Concentration of NADH in brain tissues. C) Concentration of mitochondrial complex I in H19-7 cells. D) Concentration of mitochondrial complex I in brain tissues. E) Concentration of calcium in each group of H19-7 cells. F) Concentration of calcium in each group of brain tissues. G) Relative intensity of ROS in H19-7 cells. H) Relative intensity of ROS in brain tissues. Data presented as mean \pm SD. Each experiment was repeated 3 times independently. GAPDH was used as an internal control. $p<0.05$ was set as a statistical difference; ${ }^{*} p<0.05$ compared with NC or CA group; ${ }^{\#} p<0.05$ compared with ST or CG group.

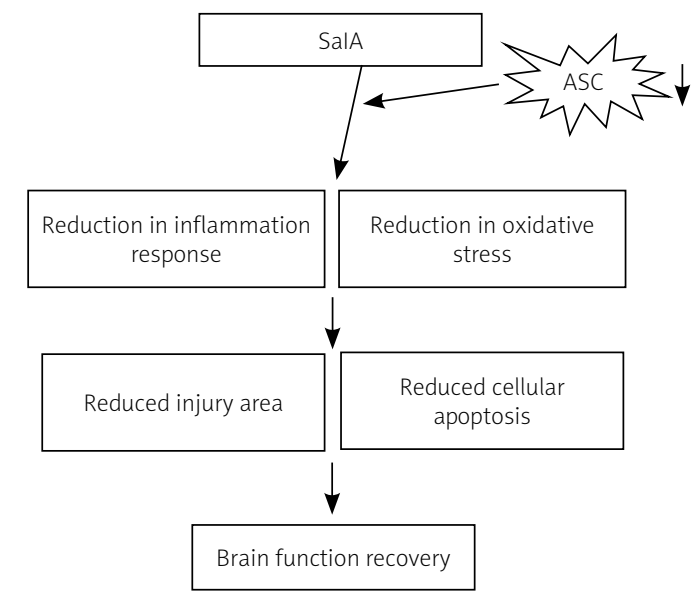

Fig. 10. Flow diagram ASC inhibition promotes salvianolic acid A function in protection of neuron cells. ability of mitochondria localisation and the ability to activate the antivirus signalling pathway as well as the function of homodimerisation and self-association [3]. The function of MAVS could be promoted by mitochondrial reactive oxygen species (mtROS), resulting in the increased expression of type I interferon, independent of RGI-I receptors, indicating that MAVS is critical for regulation of the mtROS level [4]. NLRP3 could activate the expression of IL- $1 \beta$ upon various infections and damage in multiple tissues. A previous study found that MAVS could increase the accumulation of NLRP3 in mitochondria, leading to the activation of NLRP3 inflammasome and secretion of IL-1 $\beta$ [52]. N-methyl-D-aspartate receptor is a ligand of glutamate and is primarily expressed in the human brain. NMDAR is mostly unique for its 
ability to release glutamate and for the de-polarisation of membrane, leading to the alleviation of the $\mathrm{Mg}^{2+}$ block [58]. Activation of NMDAR induces an increase in cytosolic intracellular calcium, as well as in the excitotoxicity process, further leading to the occurrence of neurodegeneration [24]. Cellular concentration of calcium is regulated by multiple mechanisms, among these the CaMK family consists of 4 members: CAMKI, PNCK, CAMK1G, and CAMK1D, of which CaMKI is highly expressed in the brain. A recent study found that growth of axon and dendrite is regulated by the concentration of calcium; blockage of CaMKI activity by KN-62 or KN-63 directly reduces the growth of axon and dendrite [46]. A previous study in vivo examined knockdown expression of CaMKI in utero and found that callosal axons originating from layers II/III of the somatosensory cortex did not extend beyond the white matter layer [39]. There was also a study which found that pharmacological inhibition or knockdown of CaMKI blocks the process of axon elongation, and this effect could be reversed by expression of constitutively active CaMKI [1]. TRAF6 was first found in 1996, and is widely expressed in brain, lung, skeletal muscle, and kidney, and mediates the expression of IL-1 signalling pathway. Although the function of TRAF6 in CNS is not clear, multiple studies found that TRAF6 is critical for the development and apoptosis of CNS. The expression is increased after 7 days of TBI, and TRAF6 could directly integrate caspase- 8 in the death domain, activating the apoptosis process [5]. Also, activation of AKT is related with cell death after TBI, and activation of AKT must be mediated by translocation from cytomembrane from cytoplasm, followed by phosphorylation through interaction with growth factor existing on the cell surface. This process could be facilitated by TRAF6, and once TRAF6 is absent, the process is damaged. Besides, TRAF6 also regulates the activation of downstream molecules such as mitogen-activated protein kinase (MAPK), c-Jun N-terminal kinase (JNK), and p38 pathways [20]. Here, we noticed that the expression which protects the function of mitochondria was up-regulated, besides, we also noticed that the expression of pro-apoptosis proteins were reduced after treatment of salvianolic acid A combined with ASC inhibition, and these effects were both found in cellular and animal models.

$\mathrm{N}$-terminal kinase was first found in the 1990s as a microtubule-associated protein kinase. JNK is activated by multiple extracellular stimuli, including cytokines, reactive oxygen species (ROS), and heat shock, and it regulates a variety of biological processes [7]. Activation of JNK is regulated by many upstream molecules, including MAP3Ks, MLKs (mixed lineage kinases), and MAPKKK (mitogen-activated protein kinase kinase kinase). JNK is regulated by multiple factors. Dual leucine zipper kinase 2 (DLK2) is a MAPK kinase, which regulates synaptic development. A previous study found that in a sciatic nerve transection model of mice, a lack of DLK significantly delayed the degeneration of axons compared to normal animals via regulation of downstream JNK signalling pathway [31]. Inhibition of JNK signalling pathway also delays axon fragmentation caused by chemotherapy; this result indicates that loss of DLK expression is axoprotective, and this effect is due to functional redundancy with related kinases of the MAPKKK family, MEKK4 and MLK3, which promotes the degeneration of axon [53]. Mitogen-activated protein kinase kinase 4 (MKK4) was first identified in Xenopus laevis embryos, and expression of MKK4 is exclusively high in CNS [19]. Deficiency of MKK4 in the embryo leads to anaemia and abnormal hepatogenesis, and deletion of MKK4 in the murine nervous system leads to the irregular alignment of Purkinje cells and delays the migration during brain development [45]; also, the development of mutant mice CNS is delayed a few days later compared with control animals, and presents with neurological disorder and death around $\mathrm{P} 20$, but prevents pathological cardiac hypertrophy through the reduction in activation of JNK signalling pathway via reduction of phosphorylation of JNK [16]. However, in this experiment, we noticed that the expression of MKK4 was not significantly changed in cells and animals after inhibition or overexpression of ASC; thus, we thought that MKK4 was not a mainly target of ASC in promoting the treatment effect of salvianolic acid A on TBI. Mixed lineage kinases (MLKs) are regulators of the JNK signalling pathway. MLK member MLK3 directly activates the JNK signalling pathway via phosphorylates in vitro, and a recent study found that overexpression of MLK3 in neuronal cells induces the apoptosis process, which is mediated by JNK signalling pathway [13]. Hippocalcin is a sensor protein that is sensitive to the concentration of cellular calcium concentration, and it is translocated to lipid membranes with increased concentration of $\mathrm{Ca}^{2+}$. Using a mouse model, a previous study found that 
deletion of hippocalcin leads to the loss of memory [17]. Hippocalcin also protects the neuro cells from the apoptosis induced by $\mathrm{Ca}^{2+}$ via interaction with neuronal apoptosis inhibitory protein (NAIP), and MLK3 could bind with hippocalcin in the C-terminal region, followed by activation of MLK3 via inhibition of the autoinhibition function of MLK3 [57]. SCG10 is the substrate of the JNK signalling pathway, and JNK also phosphorylates SCG10 at serines 62 and 73, decreasing the binding of SCG10 and tubulin, and thereby regulating the axonal microtubule dynamic instability via binding with tubulin [40]. In cultured cortical neurons, a high-level of SCG10 expression is observed while developing cells and a decreased level after synapse formation, and the expression of SCG10 is highly up-regulated with axon regeneration after injury [34]. There is also study showing that SCG10 expression is up-regulated during axonal regeneration in peripheral nervous system and CNS, while it is decreased after target re-innervation [28]. In this study, we found that pro-inflammatory cytokine expression was up-regulated after TBI, with a decrease in mitochondrial function-related molecule expression. Also, the concentration of calcium and ROS is increased after TBI. We further noticed that salvianolic acid $A$ treatment alleviates the injury caused by TBI, and inhibition of ASC enhances the effect of salvianolic acid $A$, while overexpression of ASC reduces this effect. Meanwhile, we further found that these effects might be mediated by DLK2/ MLK3/JNK signalling pathway; thus, we thought that inhibition of ASC might be a treatment target for TBI.

\section{Disclosure}

The authors report no conflict of interest.

\section{References}

1. Ageta-Ishihara N, Takemoto-Kimura S, Nonaka M, Adachi-Morishima A, Suzuki K, Kamijo S, Fujii H, Mano T, Blaeser F, Chatila TA Mizuno H, Hirano T, Tagawa Y, Okuno H, Bito H. Control of cortical axon elongation by a GABA-driven Ca2+/calmodulindependent protein kinase cascade. J Neurosci 2009; 29: 13720-13729.

2. Antolovic D, Koch M, Bohlmann I, Kienle P, Büchler M, Weitz J. Short description of an alternative simplified method for screening recombinant clones within the "AdEasy-System" by Duplex-PCR. BMC Biotechnology 2005; 5: 1.

3. Baril M, Racine ME, Penin F, Lamarre D. MAVS dimer is a crucial signaling component of innate immunity and the target of hepatitis C virus NS3/4A protease. J Virol 2009; 83: 1299-1311.

4. Buskiewicz IA, Montgomery T, Yasewicz EC, Huber SA, Murphy MP, Hartley RC, Kelly R, Crow MK, Perl A, Budd RC. Reactive oxygen species induce virus-independent MAVS oligomerization in systemic lupus erythematosus. Sci Signal 2016; 9: ra115.

5. Chen J, Wu X, Shao B, Zhao W, Shi W, Zhang S, Ni L, Shen A. Increased expression of TNF receptor-associated factor 6 after rat traumatic brain injury. Cell Mol Neurobiol 2011; 31: 269-275.

6. Chen T, Liu W, Chao X, Zhang L, Qu Y, Huo J, Fei Z. Salvianolic acid $B$ attenuates brain damage and inflammation after traumatic brain injury in mice. Brain Res Bull 2011; 84: 163-168.

7. Coffey ET. Nuclear and cytosolic JNK signalling in neurons. Nat Rev Neurosci 2014; 15: 285-299.

8. Conway KE, McConnell BB, Bowring CE, Donald CD, Warren ST, Vertino PM. TMS1, a novel proapoptotic caspase recruitment domain protein, is a target of methylation-induced gene silencing in human breast cancers. Cancer Res 2000; 60: 6236-6242.

9. Daniels BP, Jujjavarapu H, Durrant DM, Williams JL, Green RR, White JP, Lazear HM, Gale M, Diamond MS, Klein RS. Regional astrocyte IFN signaling restricts pathogenesis during neurotropic viral infection. J Clin Invest 2017; 127: 843-856.

10. Durcan TM, Fon EA. The three 'P's of mitophagy: PARKIN, PINK1, and post-translational modifications. Genes Dev 2015; 29: 989999.

11. Gururaj J. Epidemiology of traumatic brain injuries: Indian scenario. J Prog Neurosurg Neurol Neurosci 2013; 24: 24-28.

12. Hasegawa M, Kawase K, Inohara N, Imamura R, Yeh WC, Kinoshita T, Suda T. Mechanism of ASC-mediated apoptosis: bid-dependent apoptosis in type II cells. Oncogene 2007; 26: 1748-1756.

13. Hirai S, Katoh M, Terada M, Kyriakis JM, Zon LI, Rana A, Avruch J, Ohno S. MST/MLK2, a member of the mixed lineage kinase family, directly phosphorylates and activates SEK1, an activator of c-Jun N-terminal kinase/stress-activated protein kinase. J Biol Chem 1997; 272: 15167-15173.

14. Hua F, Wang J, Ishrat T, Wei W, Atif F, Sayeed I, Stein DG. Genomic profile of Toll-like receptor pathways in traumatically brain-injured mice: effect of exogenous progesterone. J Neuroinflammation 2011; 8: 42.

15. Igor K, Nor LJ, Nadiawati AR, Zubaidah HB, Mohd MR, Mohd AZ, Ainsah BO, Renad A. A mouse model of weight-drop closed head injury: emphasis on cognitive and neurological deficiency. Neural Regen Res 2016; 11: 630-635.

16. Kishimoto H, Nakagawa K, Watanabe T, Kitagawa D, Momose H, Seo J, Nishitai G, Shimizu N, Ohata S, Tanemura S, Asaka S, Goto T, Fukushi H, Yoshida H, Suzuki A, Sasaki T, Wada T, Penninger JM, Nishina H, Katada T. Different properties of SEK1 and MKK7 in dual phosphorylation of stress-induced activated protein kinase SAPK/JNK in embryonic stem cells. J Biol Chem 2003; 278: 16595-16601.

17. Kobayashi M, Masaki T, Hori K, Masuo Y, Miyamoto M, Tsubokawa H, Noguchi H, Nomura M, Takamatsu K. Hippocalcin-deficient mice display a defect in CAMP response element-binding protein activation associated with impaired spatial and associative memory. Neuroscience 2005; 133: 471-484.

18. Lazarou M, Jin SM, Kane LA, Youle RJ. Role of PINK1 binding to the TOM complex and alternate intracellular membranes in recruitment and activation of the E3 ligase Parkin. Dev Cell 2012; 22: 320-333. 
19. Lee JK, Hwang WS, Lee YD, Han PL. Dynamic expression of SEK1 suggests multiple roles of the gene during embryogenesis and in adult brain of mice. Brain Res Mol Brain Res 1999; 66: 133140.

20. Liu H, Tamashiro S, Baritaki S, Penichet M, Yu Y, Chen H, Berenson J, Bonavida B. TRAF6 activation in multiple myeloma: a potential therapeutic target. Clin Lymphoma Myeloma Leuk 2012; 12: 155-163.

21. Livak KJ, Schmittgen TD. Analysis of relative gene expression data using real-time quantitative PCR and the 2(-Delta Delta C(T)) method. Methods 2001; 25: 402-408.

22. Loane DJ, Faden Al. Neuroprotection for traumatic brain injury: translational challenges and emerging therapeutic strategies. Trends Pharmacol Sci 2010; 31: 596-604.

23. Ma Y, Liu W, Wang Y, Chao X, Qu Y, Wang K, Fei Z. VEGF protects rat cortical neurons from mechanical trauma injury induced apoptosis via the MEK/ERK pathway. Brain Res Bull 2011; 86: 441-446.

24. MacDonald JM, Beach MG, Porpiglia E, Sheehan AE, Watts RJ, Freeman MR. The Drosophila cell corpse engulfment receptor Draper mediates glial clearance of severed axons. Neuron 2006; 50: 869-881.

25. Masumoto J, Taniguchi S, Ayukawa K, Sarvotham H, Kishino T, Niikawa N, Hidaka E, Katsuyama T, Higuchi T, Sagara J. ASC, a novel 22-kDa protein, aggregates during apoptosis of human promyelocytic leukemia HL-60 cells. J Biol Chem 1999; 274: 33835-33838.

26. Masumoto J, Dowds TA, Schaner P, Chen FF, Ogura Y, Li M, Zhu L, Katsuyama T, Sagara J, Taniguchi S, Gumucio DL, Núñez G. ASC is an activating adaptor for NF- $\mathrm{B}$ and caspase-8-dependent apoptosis. Biochem Biophys Res Commun 2003; 303 69-73.

27. Martinon F, Burns K, Tschopp J. The inflammasome: a molecular platform triggering activation of inflammatory caspases and processing of prolL-beta. Mol Cel 2002; 10: 417-426.

28. Mason MR, Lieberman AR, Grenningloh G, Anderson PN. Transcriptional upregulation of SCG10 and CAP-23 is correlated with regeneration of the axons of peripheral and central neurons in vivo. Mol Cell Neurosci 2002; 20: 595-615.

29. Mantovani A, Barajon I, Garlanda C. IL-1 and IL-1 regulatory pathways in cancer progression and therapy. Immunol Rev 2018; 281: 57-61.

30. McConnell BB, Vertino PM. Activation of a caspase-9-mediated apoptotic pathway by subcellular redistribution of the novel caspase recruitment domain protein TMS1. Cancer Res 2000; 60: 6243-6247.

31. Miller BR, Press C, Daniels RW, Sasaki Y, Milbrandt J, DiAntonio A. A dual leucine kinasedependent axon self-destruction program promotes Wallerian degeneration. Nat Neurosci 2009; 12: $387-$ 389.

32. Olczak M, Poniatowski ŁA, Niderla-Bielińska J, Kwiatkowska M, Chutorański D, Tarka S, Wierzba-Bobrowicz T. Concentration of microtubule associated protein tau (MAPT) in urine and saliva as a potential biomarker of traumatic brain injury in relationship with blood-brain barrier disruption in postmortem examination. Forensic Sci Int 2019; 301: 28-36.
33. Olczak M, PoniatowskiŁ, Kwiatkowska M, Samojłowicz D, TarkaS, Wierzba-Bobrowicz T. Immunolocalization of dynein, dynactin, and kinesin in the cerebral tissue as a possible supplemental diagnostic tool for traumatic brain injury in postmortem examination. Folia Neuropathol 2019; 57: 51-62.

34. Pellier-Monnin V, Astic L, Bichet S, Riederer BM, Grenningloh G. Expression of SCG10 and stathmin proteins in the rat olfactory system during development and axonal regeneration. J Comp Neurol 2001; 433: 239-254.

35. Qi Y, Qiu Q, Gu X, Tian Y, Zhang Y. ATM mediates spermidinein-duced mitophagy via PINK1 and Parkin regulation in human fibro-blasts. Sci Rep 2016; 6: 24700.

36. Song J, Zhang W, Wang J, Yang H, Zhou Q, Wang H, Li L, Du G. Inhibition of $\mathrm{FOXO} 3 \mathrm{a} / \mathrm{BIM}$ signaling pathway contributes to the protective effect of salvianolic acid A against cerebral ischemia/reperfusion injury. Acta Pharm Sin B 2019; 9: 505-515.

37. Tabatabaei SA, Soleimani M, Alizadeh M, Movasat M, Mansoori MR, Alami Z, Foroutan A, Joshaghani M, Safari S, Goldiz A. Predictive value of visual evoked potentials, relative afferent pupillary defect, and orbital fractures in patients with traumatic optic neuropathy. Clin Ophthalmol 2011; 2011: 51021-51032.

38. Tabish SA, Nabil S. Recent advances and future trends in traumatic brain injury. Emerg Med (Los Angel) 2015; 2015: 52295237.

39. Takemoto-Kimura S, Ageta-Ishihara N, Nonaka M, AdachiMorishima A, Mano T, Okamura M, Fujii H, Fuse T, Hoshino M, Suzuki S, Kojima M, Mishina M, Okuno H, Bito H. Regulation of dendritogenesis via a lipid-raft-associated Ca 2+/calmodulin-dependent protein kinase CLICK-III/CaMKI. Neuron 2007; 54: 755-770.

40. Tararuk T, Ostman N, Li W, Björkblom B, Padzik A, Zdrojewska J, Hongisto V, Herdegen T, Konopka V, Courtney MJ, Coffey ET. JNK1 phosphorylation of SCG10 determines microtubule dynamics and axodendritic length. J Cell Biol 2006; 173: 265277.

41. Taylor CA, Bell JM, Breiding MJ, XU L. Traumatic brain injuryrelated emergency department visits, hospitalizations, and deaths - United States, 2007 and 2013. MMWR Surveill Summ 2017; 66: 1-16

42. Wang T, Lander ES, Sabatini DM. Large-scale single guide RNA library construction and use for CRISPR-Cas9-based genetic screens. Cold Spring Harb Protoc 2016; 2016: pdb.top086892.

43. Wang T, He C. TNF- $\alpha$ and IL-6: The Link between Immune and Bone System. Curr Drug Targets 2020; 21: 213-227.

44. Wang J, Zhai Q, Chen Y, Lin E, Gu W, McBurney MW, He Z. A local mechanism mediates NAD-dependent protection of axon degeneration. J Cell Biol 2005; 170: 349-355.

45. Wang X, Nadarajah B, Robinson AC, McColl BW, Jin JW, Dajas-Bailador F, Boot-Handford RP, Tournier C. Targeted deletion of the mitogenactivated protein kinase kinase 4 gene in the nervous system causes severe brain developmental defects and premature death. Mol Cell Biol 2007; 27: 7935-7946.

46. Wayman GA, Lee YS, Tokumitsu H, Silva AJ, Soderling TR. Calmodulin-kinases: modulators of neuronal development and plasticity. Neuron 2008; 59: 914-931.

47. Werner C, Engelhard K. Pathophysiology of traumatic brain injury. Br J Anaesth 2007; 99: 4-9. 
48. Wojdasiewicz P, Poniatowski ŁA, Turczyn P, Frasuńska J, Paradowska-Gorycka A, Tarnacka B. Significance of omega-3 fatty acids in the prophylaxis and treatment after spinal cord injury in rodent models. Mediators Inflamm 2020; 2020: 3164260.

49. Xiong Y, Gu Q, Peterson PL, Muizelaar JP, Lee CP. Mitochondrial dysfunction and calcium perturbation induced by traumatic brain injury. J Neurotrauma 1997; 14: 23-34.

50. Xu C, Hou B, He P, Ma P, Yang X, Yang X, Zhang L, Qiang G, Li W, Du G. Neuroprotective effect of salvianolic acid $A$ against diabetic peripheral neuropathy through modulation of Nrf2. Oxid Med Cell Longev 2020; 2020: 6431459.

51. Xu X, Yin D, Ren H, Gao W, Li F, Sun D, Wu Y, Zhou S, Lyu L, Yang M, Xiong J, Han L, Jiang R, Zhang J. Selective NLRP3 inflammasome inhibitor reduces neuroinflammation and improves long-term neurological outcomes in a murine model of traumatic brain injury. Neurobiol Dis 2018; 117: 15-27.

52. Xun C, Hu Y, Lu M, Wang S, Lv D. Study of effect of salvianolic acid $B$ on motor function recovery in rats with spinal cord injury. Biomed Res Int 2014; 2014: 931850

53. Yang J, Wu Z, Renier N, Simon DJ, Uryu K, Park DS, Greer PA Tournier C, Davis RJ, TessierLavigne M. Pathological axonal death through a MAPK cascade that triggers a local energy deficit. Cell 2015; 160: 161-176.

54. Ye Y, Xu H, Zhang X, Li Z, Jia Y, He X, Huang JH. Association between toll-like receptor 4 expression and neural stem cell proliferation in the hippocampus following traumatic brain injury in mice. Int J Mol Sci 2014; 15: 12651-12664.

55. Yonutas HM, Vekaria HJ, Sullivan PG. Mitochondrial specific therapeutic targets following brain injury. Brain Res 2016; 1640: 77-93.

56. Zhang YL, Cao YJ, Zhang X, Liu HH, Tong T, Xiao GD, Yang YP, Liu CF. The autophagy-lysosome pathway: a novel mechanism involved in the processing of oxidized LDL in human vascular endothelial cells. Biochem Biophys Res Commun 2010; 394: 377-382.

57. Zhang H, Gallo KA. Autoinhibition of mixed lineage kinase 3 through its Src homology 3 domain. J Biol Chem 2001; 276 45598-45603.

58. Zhao MG, Toyoda H, Lee YS, Wu LJ, Ko SW, Zhang XH, Jia YH, Shum F, Xu H, Li BM, Kaang BK, Zhuo M. Roles of NMDA NR2B subtype receptor in prefrontal long-term potentiation and contextual fear memory. Neuron 2005; 47: 859-872. 